\title{
Consultoria externa em reforma do Estado tem função técnica ou estratégica? Um estudo de caso*
}

\author{
Maria Eliza Gonçalves de Siqueira** \\ Pedro Lincoln C. L. de Mattos**
}

\begin{abstract}
SumÁrio: 1. Introdução; 2. A trajetória da investigação do caso; 3. As idéias da reforma do Estado no mundo; 4. Conceitos da reforma do Estado brasileiro de 1995 que inspiraram os reformadores de Pernambuco; 5. A reforma administrativa de Pernambuco; 6. A GVconsult no Programa Estadual de Desestatização; 7. As diretrizes (ou limitações?) estabelecidas pelo governo do estado para realização do projeto de reestruturação; 8. As (re)ações das "forças" políticas do estado e da sociedade ao Programa Estadual de Desestatização; 9. A forma de atuação da GVconsult nas organizações; 10. Em que resultou o Programa Estadual de Desestatização; 11. Conclusões.
\end{abstract}

Summary: 1. Introduction; 2. Case study framework; 3. State reform ideas in the world; 4. 1995 Brazilian state reform concepts that inspired the Pernambuco reformers; 5. The administrative reform in Pernambuco; 6. GVconsult and the State Destatization Program; 7. The guidelines (or limitations?) established by the state government for the restructuring project; 8 . The (re)actions of the state's political 'forces' and society in relation to the State Destatization Program; 9. GVconsult's role in the organizations; 10. What resulted for the State Destatization Program; 11. Conclusions.

Palavras - chave: consultoria organizacional ao estado; programa de desestatização em Pernambuco; reforma do Estado.

\footnotetext{
* Artigo recebido em nov. 2006 e aceito em ago. 2007.

** Mestre em administração pelo Programa de Pós-Graduação em Administração da Universidade Federal de Pernambuco (Propad/UFPE). Pesquisadora do Grupo de Estudos em Conhecimento e Consultoria Organizacional (Ecco) do Propad/UFPE. Gerente da Divisão de Desenvolvimento de Recursos Humanos da Assembléia Legislativa do Estado de Mato Grosso. Endereço: Rua das Camélias, 18 — Jardim Cuiabá — CEP 78043-105, Cuiabá, MT, Brasil. E-mail: melizamt@hotmail.com. *** Ph.D. em administração pela London School of Economics and Political Sciences, Reino Unido. Professor titular do Departamento de Ciências Administrativas da UFPE. Líder do Grupo de Estudos em Conhecimento e Consultoria Organizacional (Ecco) do Propad/UFPE. Endereço: Av. Bernardo V. de Melo, 1264/1802 — Piedade - CEP 54400-000, Jaboatão dos Guararapes, PE, Brasil. E-mail: plincoln@hotlink.com.br.
} 
KEY words: organizational consultancy for states; Pernambuco (Brazil) destatization program; state reform.

Este artigo analisa o papel da consultoria organizacional externa (GVconsult/FGV) em dois projetos de desestatização previstos no Programa de Reforma do Estado de Pernambuco, no período 1999-2000: o da Centrais de Abastecimento de Pernambuco (Ceasa-PE) e o do Centro de Convenções (Cecon). O caminho metodológico foi a aproximação gradativa ao objeto de estudo, partindo de suposições iniciais e pontos críticos que serviram de orientação para a investigação. O trabalho de campo foi constituído por 31 entrevistas semi-estruturadas, em três rodadas, e os textos submetidos a uma análise semântico-pragmática da conversação (Mattos, 2005). A história do caso mostrou que a consultoria organizacional exerceu função técnica auxiliar ao governo de Pernambuco no Programa de Reforma do Estado, de acordo com diretrizes bem definidas e limitações impostas pela equipe do governo. Constatou-se também que, apesar de os conceitos da Reforma do Estado de Pernambuco terem origem nas concepções de Estado dos mentores acadêmicos da FGV e esposadas pelo governo federal (1995-98), não foram os consultores da GVconsult que as trouxeram, mas, sim, os formuladores das políticas públicas do governo de Pernambuco que as colheram diretamente do governo federal e da FGV.

Does external consultancy in State reform have a technical or a strategic role? A case study

This article analyzes the role of Getulio Vargas Foundation external organizational consultancy services (GVconsult, São Paulo, Brazil) to two destatization projects in the Pernambuco State Reform Project during 1999-2000: at Pernambuco Produce Wholesale Market (Ceasa-PE) and at the Convention Center (Cecon). The methodological strategy was to gradually approach the object of study, so that initial assumptions and critical points guided the study. The fieldwork involved 31 semi-structured interviews, in three rounds, and the texts were submitted to a semantic and pragmatic conversation analysis (Mattos, 2005). The case history showed that the organizational consultancy had a subsidiary technical role in the State Reform Program, following clear guidelines and limitations imposed by the government team. Although the Pernambuco State Reform concepts were originated from those developed by FGV academic mentors and adopted by the federal government (1995-1998), FGVconsult consultants did not bring them themselves, but rather Pernambuco public policymakers obtained them directly from the federal government and from FGV.

\section{Introdução}

Nas últimas décadas, as empresas de consultoria organizacional vêm se espalhando pelo mundo todo e movimentando um mercado promissor. Durante a década de 1990, o mercado internacional de consultoria apresentou elevadas taxas de crescimento. Isto pode ser demonstrado pelo incremento da receita 
de US\$ 22 bilhões em 1990, para mais de US\$ 100 bilhões no ano 2000 (Donadone, 2001).

Essas empresas despontam como um dos elementos de difusão e introdução de novos arranjos organizacionais, influenciando e, muitas vezes, direcionando a agenda dos possíveis formatos organizacionais (Donadone, 2003).

A atuação das consultorias externas em projetos de reforma estrutural em empresas privadas geralmente é caracterizada pela ligação direta dos consultores à cúpula da empresa, com a qual aprofundam vínculos. Suas metodologias, nesses casos, têm orientação top-down e incluem ações de motivação e envolvimento da cúpula no desenvolvimento dos projetos, o que possibilita uma participação estratégica da consultoria.

Nas organizações públicas, por sua vez, as consultorias externas deparamse com um campo peculiar. Tal especificidade decorre especialmente de que, enquanto nas organizações privadas o poder é exercido por gestores e capitalistas, nas organizações públicas ele é partilhado entre políticos, burocratas e cidadãos (Bresser-Pereira, 2005), que atuam nesse campo, algumas vezes cooperando, em outras discordando.

De acordo com os trabalhos de Mckenna (1996), a inserção das consultorias organizacionais no setor público iniciou-se durante a II Grande Guerra, quando o governo dos Estados Unidos contratou diversos consultores para reorganizar as formas de gerenciamento das áreas militares, racionalizar a produção civil e dar suporte à expansão da administração federal ocorrida naquele período. A criação de uma comissão - a Hoover Comission - em 1947, representa um marco do relacionamento entre os dois setores, público e privado (Mckenna, 1996).

Elevar os padrões de eficiência e efetividade na intervenção pública, por meio de uma nova matriz institucional baseada no desempenho, tem sido um dos maiores desafios para os gestores públicos contemporâneos (Rezende, 2005) que comumente recorrem aos serviços de empresas de consultoria para auxiliar na desafiante tarefa de reformar o Estado. Nesse contexto, a peculiaridade do ambiente estatal é ainda mais acentuada, pois o fator político tende a ser preponderante.

Este artigo pretende desbravar o campo da consultoria organizacional externa em programas de reforma do Estado, buscando entender qual foi a função (técnica ou estratégica?) exercida pela consultoria externa no Programa Estadual de Desestatização da Reforma do Estado de Pernambuco, especialmente no caso Central de Abastecimento do Recife (Ceasa) e Centro de Convenções (Cecon), ocorrido no período de 1999-2000.

O caminho metodológico adotado aqui foi caracterizado pela aproximação gradativa ao objeto em estudo, com a realização de três rodadas de entrevistas 
não-estruturadas e semi-estruturadas. O ponto de partida foi a análise preliminar de documentos institucionais e a realização de entrevistas exploratórias que conduziram a suposições iniciais e pontos críticos do caso. No entanto, a evolução do estudo foi mostrando algumas diferenças entre as suposições do ponto de partida e os efetivos fatos do caso que serão evidenciados no decorrer deste artigo.

\section{A trajetória da investigação do caso}

Com a intenção de encontrar a história que melhor represente este caso, ${ }^{1}$ optamos por realizar um estudo aberto, de caráter incremental, em que tomamos como ponto de partida questões amplas que foram se definindo à medida que a pesquisa foi desenvolvida e os fatos foram revelados.

O primeiro passo foi a realização da análise preliminar de documentos institucionais e da primeira rodada de entrevistas exploratórias não-estruturadas, de dezembro de 2004 a março de 2005, que resultaram em suposições iniciais sobre o caso. No entanto, a história do caso apresentou algumas diferenças em relação às suposições iniciais, que serão apresentadas neste artigo.

Após o primeiro contato com o campo de pesquisa, partimos para a realização de um levantamento bibliográfico nos bancos de teses e dissertações, pesquisa nos anais dos encontros da Associação Nacional de Pós-graduação e Pesquisa em Administração (Enanpad), e leituras de textos dos mais renomados autores que tratam sobre a reforma do Estado.

Em junho de 2005, demos início a uma nova etapa de entrevistas semiestruturadas com outros atores do caso, visando a confirmação de fatos já identificados e, ao mesmo tempo, buscando identificar novos dados que pudessem estar relacionados com o objeto de estudo. Realizamos também, nessa fase, pesquisas nos dois principais jornais locais, a fim de identificar matérias do período que tratassem sobre o Programa de Reforma do Estado, iniciado no primeiro governo Jarbas Vasconcelos (1999-2002).

Por fim, fizemos a terceira rodada de entrevistas, de setembro a dezembro de 2005, que teve como objetivo aprofundar pontos mais específicos e relevantes para a conclusão da presente pesquisa. Ao todo foram 31 entrevistas realizadas com os principais atores do caso.

Para a fase de análise das entrevistas, adotamos parcialmente o modelo proposto por Mattos (2005:823-847), denominado "análise do significado se-

\footnotetext{
${ }^{1}$ Segundo Stake (1994: 245), "o propósito do estudo de caso não é representar o mundo, mas
} sim, representar o caso". 
mântico-pragmático da conversação" que parte do pressuposto que a entrevista não-estruturada ou semi-estruturada é "uma forma especial de conversação" (Mattos, 2005:826).

A etapa de validação das entrevistas, prevista nesse modelo (Mattos, 2005), foi realizada com o envio dos trechos das falas dos entrevistados, via e-mail, aos respectivos autores que responderam à pesquisadora, autorizando o uso de suas citações no texto que resultaria na recriação da história do caso.

\section{As idéias da reforma do Estado no mundo}

A partir da década de 1980, os estados nacionais foram tomados por idéias de modernização, eficiência e redução de seus aparatos governamentais, resultando em um grande movimento pró-reforma. Tal fenômeno se alastrou para os mais diversos países, de diferentes contextos, como Reino Unido, Suécia, Coréia, Estados Unidos, Nova Zelândia, até chegar ao Brasil. Quase todos os países da América Latina estiveram engajados em programas de modernização do setor público, financiados por instituições internacionais, como Banco Mundial e Banco Interamericano de Desenvolvimento-BID (Spink, 2001). A reforma do setor governamental tornou-se quase um fenômeno universal (Kettl, 2001).

Esse ímpeto reformador consistia essencialmente na redefinição do papel do Estado diante da derrocada do modelo de Estado intervencionista vigente até a década de 1970, e os problemas por ele gerados, como centralização, regulação excessiva e aumento do seu tamanho e dos seus gastos.

Segundo Abrucio (2001), quatro fatores estiveram diretamente relacionados com o declínio do Estado intervencionista. O primeiro foi a grande crise econômica mundial iniciada na década de 1970, sobretudo após a crise do petróleo, e agravada durante os anos 1980. Naquela época, a economia mundial enfrentava grande período recessivo e as políticas keynesianas mostravam-se incapazes de controlar tal situação. Como conseqüência, houve um processo de aceleração inflacionária, altas taxas de desemprego e reduzidos índices de crescimento econômico. Após décadas de expansão, o Estado mergulhou em uma crise fiscal sem precedentes - o segundo fator dessa bancarrota (Abrucio, 2001). Os estados não conseguiam mais financiar seus déficits e suas despesas, dado seu tamanho; nem atender todos os serviços demandados pela sociedade. Associada a tais fatores temos, embora em menor grau, a globalização, além da emergência de novas tecnologias que transformaram a lógica do setor produtivo, afetando o Estado e resultando em perda de parcela de seu poder de ditar políticas macroeconômicas (Abrucio, 2001). 
De acordo com Rezende (2004), a onda das reformas administrativas dos anos 1990 se diferencia das anteriores por estarem voltadas para aspectos mais amplos, como a alteração do papel do Estado, a redução dos seus custos e a implementação de um desenho institucional que permitia alterar os incentivos internos de seu funcionamento. Segundo o autor, o que se pretendia, em última instância, era a mudança de um modelo burocrático intervencionista para um modelo orientado pela performance. Kettl (1999, citado por Rezende, 2004) argumenta que, nesse ponto, reside o diferencial dessas reformas e o motivo de sua impressionante proliferação, pois os governos passaram a se preocupar em como fazer para "funcionar melhor, com menor custo".

Para Hood (1990, citado por Seabra, 2001), esse conjunto de idéias que dominou a agenda política da maioria dos países e visava fundamentalmente a transformação das burocracias do setor público, era conhecido como "nova administração pública" (new public management).

No Brasil, o modelo que tomaria a forma da "nova administração pública" encontra-se expresso no documento intitulado Plano Diretor da Reforma do Aparelho do Estado (Brasil, 1995), formulado pelo extinto Ministério da Administração Federal e Reforma do Estado (Mare), que previa mudanças nos "arranjos inter e intraorganizacionais" das instituições do aparelho estatal brasileiro, constituindo as bases da reforma administrativa de 1995 (Seabra, 2001:24).

\section{Conceitos da reforma do Estado brasileiro de 1995 que inspiraram os reformadores de Pernambuco}

Influenciado pelo movimento reformista do contexto mundial, o Estado brasileiro também ingressou na "onda" das reformas estatais.

Em essência, essa "onda" consistia na reavaliação dos estados nacionais sobre o papel do Estado na sociedade e sobre seu grau de intervenção na economia. No Brasil, esse debate tornou-se imperativo em virtude da amplitude das funções assumidas pelo Estado desenvolvimentista, caracterizado pela acentuada atuação na área produtiva, que culminou na crise estatal dos anos 1990.

Para os formuladores dessa reforma (Brasil, 1998a), a crise do Estado consistia em três aspectos principais: tratava-se de uma crise fiscal, caracterizada pela perda de crédito por parte do Estado e da sua incapacidade de realizar poupança pública; uma crise do modo de intervenção do modelo de substituição de importações; e uma crise da forma de administrar, caracterizada pelas disfunções da burocracia pública.

Assim, em resposta à crise do Estado nacional-desenvolvimentista, à crise fiscal e aos problemas gerados por uma burocracia rígida associada aos resquícios do patrimonialismo, a reforma administrativa de 1995 foi desenvolvida. 
Segundo Rezende (2004), foi uma tentativa de solução, adotada pelo Executivo Federal, para os baixos níveis de desempenho apresentados pela burocracia pública brasileira, caracterizada pela relação ineficiente entre formulação e implementação de políticas públicas e por um crônico problema de gestão fiscal, durante a década de 1990.

O Ministério da Administração Federal e Reforma do Estado (Mare) foi criado para formular e implementar essa política pública no primeiro governo Fernando Henrique Cardoso (1995-1998).

Para os formuladores dessa política (Brasil, 1998c:7), o propósito da reforma era "permitir que a administração pública se torne mais eficiente e ofereça ao cidadão mais serviços públicos com melhor qualidade". O alcance da eficiência dependia da descentralização de certas atividades executadas pelo poder público, que poderiam ser melhor executadas por outras entidades apoiadas pelo Estado.

De acordo com essa perspectiva, uma nova estrutura foi delineada para o aparelho do Estado, composta por quatro setores básicos (Brasil, 1998b):

จ o núcleo estratégico responsável pela formulação das leis e das políticas públicas, compreendendo a cúpula do governo federal, ou seja, a presidência, os ministérios, os tribunais federais, o Ministério Público e o Poder Legislativo;

- as atividades exclusivas do Estado que compreendem, como o próprio nome diz, atividades que apenas o Estado, com o uso do seu poder extroverso, poderia realizar. Encontram-se aqui, órgãos como Forças Armadas, polícia, órgãos arrecadadores, de regulamentação e entidades responsáveis por transferências de recursos;

v as atividades não-exclusivas que compreendem atividades de alta relevância à sociedade, como saúde, educação, cultura e pesquisa científica, mas que não requerem o uso do poder extroverso do Estado para exercê-las, e por isso também podem ser executadas por outros setores da sociedade (setor privado ou público não-estatal) com subsídios do Estado;

- por fim, as atividades exercidas pelas empresas estatais, de produção de bens e serviços, cujas características seguem a lógica de mercado.

Com base nessa proposta, os setores do núcleo estratégico e das atividades exclusivas do Estado permaneceriam sob o domínio estatal. As atividades exclusivas de Estado deveriam ser desempenhadas por instituições qualificadas como agências executivas, que atuariam segundo um contrato firmado com a agência formuladora. Ao núcleo estratégico cabia a formulação e a avaliação das políticas públicas, delegando sua implementação às instituições descentralizadas da administração indireta qualificadas como agências executivas (Brasil, 
1995). Em contrapartida, os serviços não-exclusivos do Estado, tanto poderiam ser prestados pela iniciativa privada, quanto por entidades do tipo "organização social", qualificadas assim por um programa denominado publicização, no qual as organizações adquiririam caráter público, porém regidas por normas do direito privado. Quanto ao setor de produção de bens e serviços, a proposta da reforma consistia na transferência dessas atividades para o domínio do mercado, por meio de programas de privatização, partindo-se do pressuposto de que as empresas estatais se tornariam mais eficientes se controladas pelo mercado e administradas privadamente.

A reforma administrativa de 1995 propunha também promover mudanças culturais e de gestão dentro das organizações públicas. No tocante à dimensão cultural, o objetivo dessa reforma era aniquilar definitivamente as práticas patrimonialistas vigentes nas organizações, e superar as amarras do modelo burocrático descrito por Weber, com a instauração de uma cultura gerencial no serviço público. Quanto à dimensão gestão, pretendia-se implementar técnicas gerenciais nas organizações por se considerar que, por meio delas, seria possível atingir a tão almejada eficiência na prestação de serviços públicos (Bresser-Pereira, 2001).

Esse tipo de gestão, que parecia ser a solução à crise da dimensão administrativa do Estado, foi denominado pelos formuladores dessa política de "administração pública gerencial" (Brasil, 1995).

\section{A reforma administrativa de Pernambuco}

\section{O contexto institucional}

Pernambuco, como outros estados da Federação, deparou-se com um quadro de graves dificuldades econômico-financeiras durante a década de 1990. A reduzida capacidade de arrecadação, em função do baixo crescimento da economia pernambucana, e problemas de evasão fiscal, decorrentes do reduzido poder de fiscalização do Estado; contrastava com a crescente demanda da sociedade por bens públicos, diante dos problemas sociais recorrentes.

A situação econômica de Pernambuco pode ser demonstrada a partir de alguns indicadores. A evolução do produto interno bruto (PIB) do estado, no período de 1990-1996, indica o reduzido crescimento da economia local. Enquanto as economias do Brasil e da região Nordeste cresciam em torno de 2,8\% e 2,4\% respectivamente, o crescimento médio da economia pernambucana foi de apenas 1,8\% (Pernambuco, 2005).

Quanto ao aspecto social, os números também são desfavoráveis. A qualidade de vida da população pernambucana, segundo o índice de renda média 
(PIB per capita), ocupava, em 1998, a quarta posição no ranking dos estados da região Nordeste, no patamar de $\mathrm{R} \$ 2,7 \mathrm{mil} / \mathrm{hab} / \mathrm{ano}$, muito abaixo da média brasileira de aproximadamente $\mathrm{R} \$ 4,8 \mathrm{mil} / \mathrm{hab} / \mathrm{ano}$, embora estivesse um pouco acima da média regional (IBGE-Sudene; citado por Pernambuco Já, 1998:11).

Associado a tais fatores estava o quadro de escassez de recursos públicos para a manutenção da máquina estatal. No ano de 1998, a receita corrente líquida não era suficiente para suprir o total da despesa do estado, incluindo folha de pessoal, custeio, gastos com a dívida pública e, ainda, ações de investimentos do governo. $O$ resultado de tal equação era um déficit na conta do estado no patamar de 27,19\%, como mostra o quadro 1 (Pernambuco,1999).

\section{Quadro 1 \\ Percentual dos gastos públicos em relação à receita corrente líquida $(\mathrm{RCL})$ do estado de Pernambuco}

\begin{tabular}{|lc|}
\hline Gastos públicos & $\begin{array}{c}\text { Comprometimento da } \\
\text { receita corrente líquida (\%) }\end{array}$ \\
\hline Pessoal & 70,40 \\
Custeio & 28,54 \\
Investimentos & 2,78 \\
Serviço da dívida & 25,54 \\
Total & 127,19 \\
\hline
\end{tabular}

Fonte: Pernambuco (1999:6).

Para agravar ainda mais a situação, medidas do governo federal reduziram as transferências automáticas de recursos para os estados-membros, com a instituição do Fundo de Estabilização Fiscal (FEF) e a não-incidência de ICMS sobre produtos exportados definida pela Lei Kandir (Pernambuco, 2000a). Portanto, o quadro financeiro estadual era realmente alarmante.

Diante dessa realidade, os opositores do governo Miguel Arraes (19951998) motivados pelo anseio de reverter esse quadro e retomar o desenvolvimento, produziram uma proposta de trabalho baseada na promessa de mudança.

Assim surge a proposta do movimento "Pernambuco Já", elaborada por um grupo de pessoas mobilizadas em torno de um ideal de mudança para Pernambuco. Segundo esse programa de governo, o primeiro passo seria a mudança radical na forma como Pernambuco era governado, que implicaria na implementação de um novo modelo de gestão e de novas ações governamentais (Pernambuco Já, 1998:21-22).

Entre as diversas linhas de ação previstas nesse programa, destaca-se a linha de ação 15, onde os significados dos termos "reforma estrutural e modernização do estado" são enfatizados, associando-os ao conceito de redimensiona- 
mento do papel do Estado na sociedade. Segundo Pernambuco Já (1998:107), a adequada reestruturação do Estado consistia na mudança do foco de suas ações, tornando-se "menos executor, menos prestador de serviços, deixando de ser responsável único e direto pelo desenvolvimento econômico e social e mantendo suas funções de coordenador, regulador, promotor e provedor dos bens e serviços públicos".

Tal proposta previa ainda a mudança de uma "administração pública burocrática, rígida e ineficiente para uma administração pública gerencial", voltada para o atendimento do cidadão; e a criação de espaços institucionais capazes de propiciar o controle social e a audiência dos diversos setores da sociedade (Pernambuco Já, 1998:107).

Portanto, é possível perceber que as concepções sobre a nova relação Estado/sociedade e o novo modelo de administração pública considerados apropriados a um ambiente democrático por esse grupo político, estavam presentes desde o período da formulação de suas políticas.

\section{$A$ "onda"2 de reforma chega a Pernambuco}

Com a vitória do grupo político liderado pelo então candidato Jarbas Vasconcelos, em 1998, e a devida constatação da situação financeira do estado de Pernambuco, tornou-se possível a propagação, no âmbito estadual, das concepções sobre o "moderno" estado indutor e a administração pública gerencial, manifestadas previamente em seu programa de governo.

Ainda no período de transição, o candidato eleito confirmou sua intenção de empreender reforma. Técnicos da equipe do governo acompanhavam as tendências das políticas nacional e internacional. Em âmbito nacional, os documentos elaborados pelo extinto Mare, como o Plano Diretor da Reforma do Estado Federal em conjunto com os denominados Cadernos Mare, cujas idéias eram capitaneadas pelo então ministro Luiz Carlos Bresser-Pereira, serviram como fonte de inspiração para a definição das políticas em Pernambuco. Além desses documentos, a Emenda Constitucional no 19, aprovada em junho de 1998, cujo teor consistia na reformulação do funcionamento da burocracia pública federal, também foi objeto de estudo desse grupo político. O relato do secretário executivo da Comissão de Reforma do Estado do período, Hélio Oliveira (entrevista, 2005), confirma o alinhamento de Pernambuco com a agenda política

\footnotetext{
${ }^{2}$ Esse subtítulo refere-se ao termo "onda global" utilizado por Kettl (2001) para expressar a impressionante difusão das idéias de reforma no setor público por diversos países, durante as décadas de 1980 e 1990, tornando-se quase um fenômeno universal.
} 
nacional: "Nós já vínhamos acompanhando a evolução, no cenário nacional, do desempenho do governo Fernando Henrique, algumas premissas que estavam sendo implementadas em nível nacional poderiam ser trazidas para o cenário estadual, e foi isso que fizemos".

As políticas internacionais também influenciaram a agenda sobre reforma do estado instaurada em Pernambuco. A participação nos encontros do Centro Latino-americano de Administração para o Desenvolvimento (Clad) ${ }^{3}$ por membros da equipe do governo foi uma das formas encontradas para sintonizar o estado com a agenda política mundial. Além disso, visitas de técnicos renomados do contexto nacional, que compunham a equipe do então ministro Bresser Pereira, foram realizadas em Pernambuco, com o intuito de difundir o conhecimento sobre reforma do estado, por meio de seminários ou de cursos na Escola de Governo, ${ }^{4}$ segundo relato do secretário adjunto de Administração e Reforma do Estado do período, Joaquim Castro (entrevista, 2005): "outro passo que nós demos foi trazer a equipe do Bresser. Basicamente, trouxemos todos eles aqui, Caio Marini, Humberto Martins, Cláudia Costin, mais de uma vez".

Com o objetivo imediato de recuperar o equilíbrio das contas públicas, o novo governo (1999-2002) priorizou ações de contenção de gastos públicos e de criação de uma estrutura legal e institucional adequada a um novo modelo de estado. Assim, em janeiro de 1999, foi encaminhado à Assembléia Legislativa do estado, um projeto de lei cujo teor consistia na primeira etapa da reforma administrativa estadual. Entre os pontos mais polêmicos do projeto estava o artigo 9, que autorizava o Poder Executivo a promover mudanças institucionais em diversos órgãos estatais, por meio de um amplo Programa de Desestatização. Entre as opções de mudança estavam a privatização, a extinção, a fusão, a cisão, a transformação, a concessão ou, ainda, a implementação de um contrato de gestão entre o estado e setores da sociedade civil. Os parlamentares da oposição reclamavam que a aprovação desse artigo representava um "cheque em branco" ao governo, já que ele permitia que este decidisse o destino de vários órgãos, sem definir a priori o que seria feito com cada um deles (Jornal do Commercio, 1999:5).

\footnotetext{
${ }^{3}$ Clad é um organismo internacional de caráter intergovernamental, integrado por 25 países da América Latina, Caribe e Península Ibérica, criado com o objetivo de promover a cooperação técnica e a formação de funcionários, bem como a reflexão, o debate e o intercâmbio de experiências e investigação sobre reforma do Estado e modernização da administração pública (Instituto Pólis, 2005).

${ }^{4}$ A Escola de Governo foi criada em 2001 pelo governo de Pernambuco com o principal objetivo de consolidar o novo modelo de gestão a ser adotado no estado (Pernambuco, 2005a).
} 
Apesar das manifestações contrárias, o governo conseguiu conquistar a maioria dos votos e aprovar o projeto que originou a Lei no 11.629/99, autorizando a implementação do Programa Estadual de Desestatização, que tinha como principal objetivo atenuar a presença do Estado no setor de produção de serviços públicos, e atrair investimentos privados para o desenvolvimento de infra-estrutura de serviços essenciais. E, ainda, contribuir para a reestruturação das finanças públicas estaduais (Pernambuco, 2000a).

Foram os primeiros passos em direção a um amplo programa de reforma administrativa instaurado no governo Jarbas Vasconcelos (1999-2002), que previa ainda outros projetos, tais como: o programa de ajuste fiscal; o programa de modernização administrativa; e o programa de valorização do servidor.

Para coordenar tal política pública, o governo instaurou a Comissão Diretora da Reforma do estado (CDRE), composta pelo vice-governador e por alguns secretários de Estado (Pernambuco, 2000a).

Seguindo os moldes do governo federal, os reformadores de Pernambuco elaboraram o plano diretor da reforma estadual, onde consta o motivo da realização dessa política que seria a retomada da capacidade do governo de promover políticas públicas (governança), naquele momento comprometida, em virtude da situação caótica das finanças estaduais (Pernambuco, 2000a). Para isso, segundo os reformadores, era preciso que o estado assumisse sua nova posição de "gestor de políticas públicas" e "indutor do desenvolvimento econômico e social", objetivo central da reforma que norteou todas as ações relativas às mudanças do aparelho estatal pernambucano (Pernambuco, 2000a:15-18).

Assim, ações reformistas foram delineadas pela referida Comissão Diretora, guiadas por três objetivos principais (Pernambuco, 2000a):

- realizar o ajuste fiscal, a fim de alcançar o equilíbrio entre receita e despesa;

v adotar um novo modelo de gestão com práticas gerenciais inspiradas na administração de empresas, voltadas para a eficiência, a produtividade, e para o "cidadão-cliente";

v e mudar a forma de intervenção do Estado na economia, por meio da alteração de seu foco de atuação e da implantação de uma nova estrutura no estado.

Essa nova estrutura organizacional consistia essencialmente na distinção das atividades do Estado em exclusivas e não exclusivas, em função de sua natureza, em sintonia com o modelo adotado em nível federal.

De acordo com tal modelo, as atividades exclusivas do estado, que compreendem as atividades próprias do nível estratégico do governo e as atividades que somente o estado pode realizar com o uso do seu poder extroverso, ficariam 
sob responsabilidade das agências governamentais: executivas ou reguladoras. $\mathrm{E}$ as atividades não-exclusivas seriam delegadas para outras instituições, com a formação de redes entre o governo, a sociedade e o mercado. Assim, certas atividades produtivas de bens e serviços que até então eram realizadas diretamente pelo governo de Pernambuco, por organizações que integravam sua estrutura administrativa, seriam transferidas para outros setores da sociedade, por meio do Programa Estadual de Desestatização (Pernambuco, 2000a).

\section{A GVconsult no Programa Estadual de Desestatização}

Diante da tarefa de promover a reforma do Estado em Pernambuco, começando pelo Programa Estadual de Desestatização, a Comissão Diretora da Reforma (CDRE) decide contratar os serviços de uma consultoria organizacional externa a fim de obter suporte técnico para a análise do modelo institucional mais apropriado para as organizações e a preparação para a desestatização.

A reputação de competência técnica da consultoria organizacional da Escola de Administração de Empresas de São Paulo (Eaesp), vinculada à Fundação Getulio Vargas (FGV) - GVconsult - em processos de desestatização e de reforma administrativa, foi fator decisivo para sua contratação, realizada pelos reformadores de Pernambuco que dispunham de pouco conhecimento na área e, por isso, decidiram apoiar-se em uma instituição legitimada. Além disso, a marca FGV poderia facilitar a realização e a aceitação das idéias de reestruturação pelas pessoas que compunham a máquina pública estatal, conforme relatado pelo secretário-executivo da Comissão de Reforma do período, Helio Oliveira (entrevista, 2005): "nós utilizamos a experiência deles, a experiência de penetração, o nome, porque se a gente não coloca a 'bandeirinha' da Fundação, como é que a gente ia vender isso para fora".

Os primeiros contatos do governo de Pernambuco com a FGV foram realizados por intermédio de uma consultoria organizacional local, pois não existia em Recife escritório de representação da instituição. Essa consultoria tornou-se responsável pela coordenação local do projeto de reestruturação.

A partir de então, o processo de contratação da consultoria foi desencadeado com a apresentação de uma proposta de trabalho pela FGV ao governo de Pernambuco, que resultou na assinatura do Contrato no 71/99, cujo objeto consistia na contratação dos serviços de consultoria da FGV para a realização dos "projetos de modelagens" na organização Companhia de Abastecimento e de Armazéns Gerais do Estado de Pernambuco (Ceagepe) e na unidade organizacional Centro de Convenções (Cecon) da Empresa de Turismo de Pernambuco (Empetur), em duas etapas distintas: a primeira tratava-se da avaliação 
econômico-financeira das entidades, e a segunda, do suporte à implementação das mudanças (Fundação Getulio Vargas, 1999). Com esse projeto, pretendiase reestruturar a organização Ceagepe e a unidade Cecon a fim de que elas se tornassem atrativas aos grupos privados a ponto de serem absorvidas pelo setor, saindo da estrutura do Estado.

A decisão de incluir essas organizações entre as primeiras a serem avaliadas no Programa de Desestatização, não ocorreu por motivo fortuito. Tais organizações eram responsáveis por elevado déficit público, em função de suas estruturas caras e ineficientes.

Nesse período, a Ceagepe era uma sociedade de economia mista estadual, vinculada à Secretaria de Produção Rural e Reforma Agrária do Estado, composta por 20 unidades de armazenagem e de abastecimento, entre elas a Ceasa e o silo portuário (Pernambuco; Fundação Getulio Vargas, 1999a).

A atuação dessa organização se restringia a dois setores específicos e relevantes da economia agrícola do estado: a comercialização em atacado de alimentos, em especial, de hortifrutigranjeiro, e o armazenamento de produtos agrícolas, principalmente de grãos utilizados como matéria-prima industrial, destinada ao processamento de alimentos para consumo humano e animal (Pernambuco; Fundação Getulio Vargas, 1999a).

Na ocasião de sua reestruturação, a unidade de abastecimento Ceasa funcionava como um terminal de comercialização atacadista, em que produtores e comerciantes (chamados "permissionários") alugavam seus espaços para fazer negócios com os usuários que ali se dirigiam.

O Centro de Convenções foi criado durante a década de 1970, com a finalidade de tornar-se um espaço destinado a disseminar cultura, negócios e lazer no estado. Em 1992, a entidade Centro de Convenções, Feiras e Exposições (Cecon) passou a fazer parte da Empresa de Turismo de Pernambuco (Empetur), formando uma única instituição, uma sociedade de economia mista vinculada à Secretaria de Desenvolvimento Econômico, Turismo e Esportes do estado, que tinha como principal objetivo promover o fomento do turismo, mantendo-se alinhada à política de desenvolvimento econômico e social do estado (Pernambuco; Fundação Getulio Vargas, 1999b).

\section{As diretrizes (ou limitações?) estabelecidas pelo governo do estado para realização do projeto de reestruturação}

Realizada a contratação da consultoria GVconsult, a Comissão Diretora da Reforma definiu os caminhos pelos quais a consultoria deveria seguir para a execução dos trabalhos de reestruturação, com a definição de algumas diretrizes. 
A primeira delas referia-se à forma de atuação dos consultores nas organizações estatais durante o desenvolvimento do projeto. Essa diretriz consistia em promover um processo de trabalho participativo, com o envolvimento dos funcionários e dirigentes. A intenção do governo era evitar que a consultoria, com sua vasta experiência, apresentasse uma "solução" previamente estabelecida, sem levar em consideração as peculiaridades de cada organização. Nesse processo participativo, os funcionários teriam a oportunidade de discutir e opinar sobre formas de aprimoramento das instituições e possíveis modelos para melhoria de sua performance, além de adquirir conhecimento técnico com os consultores. Um dos responsáveis pela contratação da consultoria, Hélio Oliveira (entrevista, 2005) citou de forma clara essa primeira orientação: "nós não queríamos nenhuma 'receita de bolo', nada que viesse pronto de São Paulo para ser cumprido aqui, esse era o requisito. Nós queríamos um processo participativo, onde a empresa crescesse".

A Lei no 11.629/99, que instituiu o Programa Estadual de Desestatização, também serviu de orientação para a GVconsult na realização desse projeto, pois nela (art. 9º) estavam contidos os modelos institucionais que as entidades poderiam assumir após sua reestruturação.

Mas não bastava definir um dos modelos previstos na lei, era preciso atender a dois requisitos essenciais estabelecidos pelo governo. O modelo proposto deveria possibilitar o alcance de dois objetivos simultâneos: um formato institucional que proporcionasse tanto "a maximização da função econômicofinanceira", quanto "a maximização da função social" das organizações. Ou seja, o novo modelo deveria proporcionar meios das instituições se tornarem auto-sustentáveis, com geração de seus próprios recursos, mas por meio da realização de atividades de fomento à economia local.

A quarta diretriz referia-se ao aspecto conceitual a ser adotado no projeto da consultoria. Definiu-se que as mudanças propostas pela GVconsult deveriam estar baseadas nas idéias contidas no Plano Diretor da Reforma estadual, documento que definiu as linhas de ação e os princípios do Programa de Reforma Estatal. A conformidade da atuação da GVconsult com essa diretriz está reconhecida em um dos relatórios elaborados pela consultoria (Pernambuco; Fundação Getulio Vargas, 2000a:75):

o que norteia o trabalho desenvolvido pela GVconsult é a idéia de um estado instrumentalizado por meio de um sistema organizacional-administrativo, baseado na eficiência, eficácia e socialmente justo e externamente controlado, capaz de superar a visão arcaica de um Estado clientelista e burocrático por uma perspectiva de gestão pública orientada para resultados socialmente desejados. 
Por fim, associada às referidas orientações, havia a determinação política do governador Jarbas Vasconcelos quanto à possibilidade de demissões de servidores públicos em virtude do Programa Estadual de Desestatização. Segundo ele, promover demissões de funcionários a fim de ajustar as contas públicas, seria o último recurso do Programa de Reforma. Tal deliberação política pode ser considerada uma diretriz para a atuação da consultoria organizacional, já que ela tinha a tarefa de auxiliar na reestruturação das organizações, sem, no entanto, poder tocar no delicado aspecto "quadro de pessoal". Essa determinação pode ser constatada no depoimento do governador Jarbas Vasconcelos (Diário de Pernambuco, 4 jul. 1999:D7): "Você me pergunta se eu descarto as demissões? Não, mas eu reitero o que tenho dito. Não quero fazer. Eu quero levar à exaustão as medidas de ajuste da máquina para evitar demissões" .

É possível notar, a partir daí, a dimensão política realçada no campo do governo de Pernambuco, especialmente no Programa Estadual de Desestatização. A posição do chefe do Poder Executivo estadual diante da alternativa de retirada de pessoas do quadro funcional, demonstra nitidamente seu perfil preponderantemente político, refletido no modo de condução do Programa de Reforma Administrativa. Essa característica típica do contexto de Estado, que o diferencia muito do ambiente do setor privado, impacta a ação das consultorias que atuam nesse campo, já que impõe certas limitações em suas atuações.

\section{As (re)ações das "forças" políticas do estado e da sociedade ao Programa Estadual de Desestatização}

Com a instauração do Programa Estadual de Desestatização, alguns presidentes de estatais deficitárias mostraram-se resistentes à possibilidade de o governo se desfazer dos ativos públicos sob seu comando e procuraram defendê-los.

No caso da Ceasa, o presidente da Ceagepe defendeu sua permanência argumentando que esta organização poderia tornar-se auto-sustentável, através do aumento da arrecadação, mantendo a importante função reguladora de preços do mercado hortifrutigranjeiro (Ribeiro, 7 fev. 99:A4).

Compartilhando de opinião semelhante, o presidente da Empetur se posicionou contrário à idéia de privatização da unidade Centro de Convenções que, para ele, era um importante instrumento indutor do desenvolvimento econômico regional, estando aí a principal razão de sua discordância. Seu argumento era baseado na idéia de que um evento realizado no Centro de Convenções contribui sobremaneira para a geração de recursos ao estado, já que um congressista, ao visitar Recife, gasta com alimentação, hotelaria, transporte, entre outras despesas, injetando um volume considerável de recursos na economia local. Logo, 
segundo ele, com a manutenção do Centro de Convenções sob seu domínio, o governo de Pernambuco estaria exercendo seu papel legítimo de promotor do desenvolvimento estadual. Tais argumentos podem ser verificados no relato do então presidente da Empetur, Frederico Loyo (entrevista, 2005):

O Centro de Convenções mostrou e demonstrou que seria um absurdo se falar em privatização do centro antes que se tivesse um estudo apurado dos reflexos diretos e indiretos na economia de Recife e Olinda em relação aos eventos ali realizados. O Centro de Convenções não se mede por sua receita operacional, [...] é uma âncora para o desenvolvimento do turismo de negócio de uma região.

Presidentes de outros órgãos incluídos no Programa de Desestatização também manifestaram seus descontentamentos quanto à possibilidade de privatização dessas organizações (Ribeiro, 1999).

Diante desses posicionamentos, o secretário de Administração e Reforma do Estado advertiu que as manifestações de alguns presidentes, contrárias ao Programa de Desestatização, eram "individuais e isoladas, fruto da inobservância da determinação do governador Jarbas Vasconcelos, que está pronto a levar esse processo à frente, a todo custo" (Romão, 7 fev. 1999:A4). Pois, segundo ele, "o Programa de Desestatização, de redefinição do modelo de estado, é um dos alicerces do governo Jarbas" (Romão, 7 fev. 1999:A4).

Não só os presidentes das organizações passíveis de privatização demonstravam suas preocupações, os funcionários dos órgãos estatais também temiam por seus destinos após a desestatização. A reforma administrativa era o "fantasma que rondava os servidores públicos" (Diário de Pernambuco, 31 dez. 1998:A2) de Pernambuco. Essa definição demonstra nitidamente o estado de alerta em que se encontravam os funcionários diante da possibilidade de demissões.

Os funcionários do Centro de Convenções, que já tinham passado por uma mudança institucional traumática, dada a forma abrupta de sua realização (a incorporação do Cecon à Empetur em 1992), estavam assustados com a possibilidade de nova separação e posterior privatização dessa unidade. A ansiedade vigorava entre os servidores, que já imaginavam a decisão drástica do governo de fazer demissões em massa.

A situação não foi diferente no caso da Ceasa. Ao constatar que a Ceagepe estava no rol das empresas "privatizáveis", os funcionários, "experientes" em processos de fusão e cisão, também se preocuparam com a possibilidade de demissões, conforme relatado pelo presidente da organização no período, Charles Ribeiro (entrevista, 2005): "o clima dos funcionários era de apreensão, de temor, porque, como a empresa em si, o nível de idade era um pouco avançado, o pessoal imaginou, na hora que isso for vendido, simplesmente o pessoal vai descartar a gente". 
Outras forças contrárias à reforma administrativa atuavam na esfera estatal. Representantes sindicais dos servidores públicos argumentaram que tal reforma nada mais era do que uma maneira encontrada pelo governo de delegar poderes à iniciativa privada e de reduzir suas atribuições. Afirmaram ainda que, com a flexibilização da gestão e a conseqüente facilidade de contratar funcionários, as empresas públicas poderiam se tornar verdadeiros "cabides" de empregos (Jornal do Commercio, 26 fev. 2000).

Diante do ambiente de instabilidade entre os servidores estatais, diversas críticas ao governo do estado despontaram nos jornais locais durante o período da reforma (Rocha, 1 out. 1999:B2).

Ciente do quadro de reações dos diversos segmentos da sociedade, a equipe do governo de Pernambuco procurou enfatizar, por diversas vezes, na imprensa local, seu empenho em realizar o ajuste fiscal sem precisar recorrer à redução do quadro de pessoal (Diário de Pernambuco, 14 mar. 1999; Vasconcelos, 14 mar. 1999; Jornal do Commercio, 23 mar. 1999; Vasconcelos, 4 jul. 1999). Mesmo assim, a desconfiança imperava no ambiente das organizações estatais.

\section{A forma de atuação da GVconsult nas organizações}

Uma das características mais marcantes do projeto de reestruturação das unidades organizacionais Ceasa e Cecon foi a forma descentralizada com que a consultoria organizacional atuou. Como se tratava de um trabalho bastante amplo, que exigia a presença freqüente de consultores nas organizações coletando informações e interagindo com os funcionários e dirigentes na construção de uma proposta de reestruturação, o projeto demandou a descentralização das atividades e a participação de consultores especializados em diversas áreas.

Os trabalhos foram divididos por áreas técnicas e terceirizados para consultores locais que atuaram sob a coordenação geral da GVconsult e a coordenação local da empresa de consultoria pernambucana Brasil Consult.

Do lado do governo, o projeto foi articulado nas instâncias da Comissão Diretora da Reforma do Estado (CDRE), em especial, da vice-governadoria e da Secretaria de Administração e Reforma do Estado (Sare), com o apoio das comissões executivas da reforma: a Comissão de Reforma do Estado (CRE) e a Comissão de Controle das Estatais (Cest).

Nas organizações-alvo do projeto, foram instituídas comissões de funcionários, compostas por técnicos de cada setor, com a finalidade de fornecer informações sobre a organização e desenvolver o trabalho em parceria com os consultores organizacionais. 
Em cada organização estatal, havia um grupo de consultores atuando. Várias frentes de trabalho foram montadas para atender as etapas do projeto.

A cada etapa concluída, a consultoria apresentava um relatório dos trabalhos realizados nas organizações. O primeiro deles foi o relatório de progresso (R1), de dezembro de 1999, em que constava a conclusão da primeira fase do projeto, que compreendia a análise estratégica do negócio, a análise crítica dos processos organizacionais, bem como a apresentação da minuta do edital para a seleção do agente de colocação das organizações no mercado (Pernambuco; Fundação Getulio Vargas, 1999a, 1999b).

O relatório foi apresentado aos dirigentes das organizações, que manifestaram seu descontentamento com o diagnóstico elaborado pelos consultores. O fato de o primeiro relatório (R1) apontar os problemas de cada organização ocasionou a reação dos dirigentes que viram nos consultores a figura de um "auditor", apontando erros e deficiências de sua gestão. Além disso, tal parecer poderia resultar na decisão do governo de retirar da estrutura do estado essas organizações ineficientes, o que não era a intenção dos dirigentes.

No entanto, diante da situação deficitária da Ceasa, seus dirigentes procuraram implementar algumas mudanças no decorrer do projeto, com o intuito de melhorar o desempenho e, conseqüentemente, evitar a extinção ou a privatização da organização. Assim, tais dirigentes decidiram aproveitar a oportunidade de ter em mãos um relatório de avaliação da organização e ainda dispor de momentos de debates e orientação com os consultores organizacionais para aprimorar as idéias relativas às formas de incrementar a arrecadação da Ceasa. As orientações da consultoria foram consideradas relevantes indicações para obtenção de um melhor desempenho.

A postura adotada pelos dirigentes da Ceasa frente ao trabalho da consultoria, diverge da adotada pelos dirigentes da unidade Cecon. Tal postura decorre da discordância deles sobre a forma com que o Centro de Convenções estava sendo avaliado pelos consultores. Segundo eles, o estudo realizado pela consultoria se restringia a analisar o resultado operacional da unidade e não sua contribuição para o fomento do turismo de negócio da região, como relatado pelo presidente da instituição no período, Frederico Loyo (entrevista, 2005): "Eu acho que a consultoria não fez um estudo que eu desejava. Pelo que eu me lembre, ela apenas fez um estudo superficial, e não um estudo de repercussão financeira [...]. Ela apenas olhou para as receitas e as despesas". Em virtude da discordância com a consultoria, nenhuma sugestão de mudança apresentada pelos consultores organizacionais foi implementada no Cecon.

Dando continuidade ao projeto, a consultoria apresentou o segundo relatório de progresso (R2), em julho de 2000, cujo teor consistia nas avaliações jurídica, econômico-financeira e patrimonial das organizações. Segundo seu 
teor, os novos modelos das organizações seriam baseados nas idéias contidas no Plano Diretor da Reforma do Estado de Pernambuco, seguindo os moldes da estrutura apresentada no documento, caracterizada pela distinção entre atividades exclusivas e não-exclusivas de estado, inspirada no modelo do governo federal, da reforma administrativa de 1995 (Pernambuco; Fundação Getulio Vargas, 2000a, 2000b).

De acordo com tais diretrizes, a consultoria elaborou o terceiro relatório de progresso (R3), sugerindo o modelo institucional "concessão de uso de bem público" para as duas unidades organizacionais, em virtude da equipe do governo ter reconhecido a relevância da manutenção desses órgãos, considerados bens públicos, optando por transferir apenas a gestão para a iniciativa privada, e não todo o seu patrimônio, que continuaria estatal (Pernambuco; Fundação Getulio Vargas, 2000c, 2000d). É oportuno destacar que o modelo proposto para as organizações estava entre aqueles inicialmente cogitados pelo governo de Pernambuco, conforme noticiado na imprensa local em março de 1999 (Diário de Pernambuco, 11 mar. 1999). Isso sugere que, dadas as diretrizes bem definidas pelo governo no projeto de reestruturação, a consultoria teve seu espaço de atuação bastante limitado, especialmente quanto à proposição de modelos para as organizações.

Diante da possibilidade da Ceagepe e sua unidade Ceasa serem transferidas para a gestão privada, técnicos dessa organização se reuniram para elaborar uma avaliação minuciosa sobre as proposições expressas no segundo relatório de progresso (R2) que apontava tal sugestão. Vários aspectos foram questionados pela equipe técnica, que se preocupou em discutir desde questões mais amplas, como a temática da privatização para alguns setores da economia, até aspectos mais específicos, como o valor atribuído ao patrimônio das unidades da Ceagepe (Pernambuco, 2000b). Esse relatório foi encaminhado, posteriormente, à Comissão Diretora da Reforma (CDRE) para ser apreciado, com o objetivo de tentar influenciar a decisão da cúpula e evitar a privatização da Ceasa.

No caso Cecon, os técnicos da comissão não se mobilizaram para fazer avaliação similar, pois não tiveram acesso aos relatórios elaborados pela consultoria, que ficaram restritos à cúpula do governo.

\section{Em que resultou o Programa Estadual de Desestatização}

Concluído o trabalho da GVconsult nas unidades Ceasa e Cecon, em dezembro de 2000, os relatórios foram encaminhados à Comissão Diretora da Reforma (CDRE) para efetiva implementação dos modelos propostos.

Em meados de 2002, dando continuidade ao Programa de Reforma Administrativa, membros da Comissão Diretora da Reforma (CDRE) se reuniram em 
torno de uma nova proposta de reorganização do estado, que seria apresentada no segundo mandato de Jarbas Vasconcelos, caso fosse reeleito.

Com a reeleição confirmada, a referida proposta foi promulgada, originando a Lei Complementar no 049/03, que previa, entre outros aspectos, a implantação do modelo "gerencialismo público" para a gestão pública estadual, bem como, um novo desenho institucional caracterizado pela concentração da atuação do estado nas atividades de formulação e coordenação de políticas públicas (Pernambuco, 2003:28-30).

Nessa lei estavam as definições sobre os destinos das organizações previstas no Programa Estadual de Desestatização. Entre os órgãos extintos estava a Ceagepe, permanecendo apenas sua área de abastecimento, executada pela Ceasa, que tomaria um novo formato institucional (Pernambuco, 2003). Quanto ao Cecon, definiu-se por sua permanência como unidade organizacional da Empetur, que manteve a configuração de sociedade de economia mista (Pernambuco, 2003).

No caso Ceasa, o governo decidiu transferir a gestão da organização para outro segmento da sociedade, retirando do estado a função de realizar diretamente a atividade de comercialização e abastecimento de alimentos. No entanto, a opção de privatização encontrou fortes opositores que acreditavam não ser essa a melhor solução para a unidade Ceasa, conforme evidenciado nos argumentos do relatório crítico elaborado por seus técnicos (Pernambuco, 2000b). Assim, a solução encontrada pela Comissão Diretora de Reforma (CDRE) foi o modelo institucional "organização social", pois por meio dele seria possível transferir a execução da atividade à outra entidade, retirando-a da atribuição do estado e, ainda, conseguir competência técnica para gerir o negócio, realizado pelos próprios técnicos da Ceasa, que possuíam vasta experiência e, sobretudo, tinham se engajado no processo de mudança proposto pela equipe da reforma do estado durante o projeto da consultoria e tinham assimilado as concepções próprias da lógica de mercado.

No caso Cecon, em função da convicção política contrária à proposta de desestatização, baseada na idéia sobre o relevante papel do Cecon para a economia do estado, e na crença de que a unidade só poderia exercê-lo se mantida sob domínio estatal, o presidente da instituição na época e o secretário de Desenvolvimento Econômico, Turismo e Esportes se opuseram ao projeto e aos argumentos dos adeptos da ideologia do estado "indutor de políticas públicas" (ao invés de "executor"), propostos pela equipe da reforma estadual. O depoimento do secretário de Desenvolvimento Econômico, Turismo e Esportes do estado, Carlos Eduardo Cadoca (entrevista, 2005) confirma:

A Fundação Getulio Vargas, de fato, sugeriu a privatização do Centro de Convenções, mas, na condição de secretário de Desenvolvimento Econômico e Turismo 
do Estado de Pernambuco, à época, fui contra a indicação e levei argumentos ao governo para que a instituição fosse preservada dentro da estrutura pública.

\section{Conclusões}

A reforma administrativa do estado de Pernambuco, da qual o Programa Estadual de Desestatização consistiu em peça fundamental, apresentou características muito similares à reforma do Estado brasileiro, implementada a partir de 1995.

Com a contratação da consultoria organizacional, para auxiliar no Programa Estadual de Desestatização, vinculada à Fundação Getulio Vargas de São Paulo (FGV), instituição de origem dos mentores da reforma federal, não seria difícil imaginar que tal consultoria poderia ter sido a responsável pela inserção desses conceitos no governo pernambucano. No entanto, os dados da pesquisa sugerem que, apesar das bases conceituais da reforma administrativa de Pernambuco terem origem nas concepções de Estado defendidas pelo governo federal (1995-1998) e os consultores organizacionais pertencerem à FGV, não foram os consultores que se inspiraram nos mentores da reforma federal, suposição elaborada no início da pesquisa, mas sim a equipe do governo de Pernambuco que encontrou nesses conceitos uma possível solução para a melhoria do estado.

A história do Programa Estadual de Desestatização nas unidades organizacionais Ceasa e Cecon mostrou também que a consultoria organizacional da FGV exerceu um papel relativamente discreto no Programa de Reforma Administrativa pernambucano, ou seja, a GVconsult não desempenhou uma função estratégica no processo como comumente ocorre nas organizações do setor privado onde as consultorias dispõem de maior espaço de atuação, mas apenas exerceu uma função técnica auxiliar e bastante específica ao governo do estado na implementação de suas deliberações. Várias são as evidências que levaram a tal conclusão:

- grande parte dos consultores que atuaram nas unidades organizacionais era de consultores locais, coordenados por consultores da GVconsult, que transmitiram suas orientações, mas que, de fato, não tiveram presença atuante nas organizações;

v as concepções sobre reforma administrativa foram formuladas pela equipe do governo desde a época do programa de governo "Pernambuco Já" e do período de transição. Isso significa que essas idéias já estavam definidas na ocasião da inserção da consultoria no governo do estado e serviram como orientação para a execução do projeto de reestruturação; 
v a atuação da GVconsult foi bastante específica, pois ela atuou apenas em um pequeno segmento dentro do amplo Programa de Reforma Administrativa de Pernambuco, que envolvia vários projetos e outras organizações também incluídas no Programa Estadual de Desestatização;

v a diretriz do governo exposta à consultoria sobre o modelo institucional proposto para as unidades organizacionais, que deveria atender os requisitos "auto-sustentabilidade" e manutenção da "função social", pode ser encarada como uma forma de restrição à atuação da consultoria já que delimitou o modelo a ser proposto para as organizações;

v o modelo proposto pela consultoria para as unidades organizacionais, que consistiu na "concessão de uso de bem público", não foi efetivamente adotado pelo governo do estado;

v a GVconsult esteve inserida, durante a realização do projeto, no meio de um campo constituído por diversas "forças" políticas, que agiram de diferentes formas, ora limitando, ora permitindo a atuação dos consultores, o que ocasionou repercussões no resultado final, consistindo, até mesmo, em fator decisivo para o "insucesso" do projeto de privatização das unidades organizacionais estudadas.

Portanto, esse caso demonstra de forma esclarecedora a peculiaridade da atuação de uma consultoria organizacional no ambiente de estado, em especial, em programas de reforma, fortemente caracterizado por seu aspecto político.

Por fim, devemos destacar que a participação das consultorias organizacionais em um ambiente de setor público tem uma configuração bem específica. Ela se insere em um campo de forças políticas muito mais complexo, que a condiciona. Diferente do que acontece quando ela atua no setor privado, onde dispõe de um poder muito maior, e pode definir boa parte das mudanças estruturais e estratégicas da organização. No ambiente estatal, ela pode encontrar "espaços" de um lado e "limitações" de outro. Isso restringe e diferencia bastante sua função.

\section{Referências bibliográficas}

ABRUCIO, Fernando Luiz. Os avanços e os dilemas do modelo pós-burocrático: a reforma da administração pública à luz da experiência internacional recente. In: BRESSER-PEREIRA, Luiz C.; SPINK, Peter (Orgs.). Reforma do Estado e administração pública gerencial. 4. ed. Rio de Janeiro: FGV, 2001.

ASSEMBLÉIA dá "carta branca" a Jarbas. Jornal do Commercio, Recife, 20 jan. 1999. Política, p. 5. 
BRASIL. Presidência da República. Ministério da Administração e Reforma do Estado. Plano Diretor da Reforma do Aparelho do Estado. Brasília: Imprensa Oficial, 1995.

- Ministério da Administração Federal e Reforma do Estado. Organizações sociais. Cadernos MARE, n. 2. 4. ed. Brasília: Mare, 1998a.

. Ministério da Administração Federal e Reforma do Estado. Exposição no Senado sobre a reforma da administração pública. Cadernos MARE, n. 3. Brasília: 1998b.

. Ministério da Administração Federal e Reforma do Estado. A reforma do aparelho do estado e as mudanças constitucionais: síntese \& respostas a dúvidas mais comuns. Cadernos MARE, n. 6. Brasília: Mare, 1998c.

BRESSER-PEREIRA, Luiz Carlos. Da administração pública burocrática à gerencial. In: BRESSER-PEREIRA, Luiz C.; SPINK, Peter (Orgs.). Reforma do Estado e administração pública gerencial. 4. ed. Rio de Janeiro: FGV, 2001.

. Reforma da gestão e avanço social em uma economia semi-estagnada. In: LEVY, Evelyn; DRAGO, Pedro Aníbal (Orgs.). Gestão pública no Brasil contemporâneo. São Paulo: Fundap-Casa Civil, 2005.

DONADONE, Júlio C. "Os hunos já chegaram!": dinâmica organizacional, difusão de conceitos gerenciais e atuação das consultorias. 2001. 123f. Tese (Doutorado em Engenharia de Produção) - Escola Politécnica, Universidade de São Paulo, São Paulo, 2001.

. O mercado internacional de consultorias nas últimas décadas: crescimento, diversificação e formas de disputa. Caderno de Pesquisas em Administração, São Paulo, v. 10, n. 2, p. 1-15, abr./jun. 2003.

FAZENDA ampliará cobrança de impostos. Jornal do Commercio, Recife, 23 mar. 1999. Economia \& Negócios, p. 3.

FGV avalia programa de desestatização. Diário de Pernambuco, Recife, 11 mar. 1999. Política, p. A5.

FUNDAÇÃO GETULIO VARGAS. Escola de Administração de Empresas de São Paulo. GVconsult. Proposta no 91/99. São Paulo, 1999.

GOVERNO vai dar mais autonomia administrativa para Ipem e IPA. Cabide. Jornal do Commercio, Recife, 26 fev. 2000. Economia, p. 3.

IMPACTO de pacotes do governo é tímido. Diário de Pernambuco, Recife, 14 mar. 1999. Política, p. A3.

INSTITUTO PÓLIS. Clad. Disponível em: <www.polis.org.br> . Acesso em: 10 dez. 2005. 
KETTL, Donald F. A revolução global: reforma da administração do setor público. In: BRESSER-PEREIRA, Luiz C.; SPINK, Peter (Orgs.). Reforma do Estado e administração pública gerencial. 4. ed. Rio de Janeiro: FGV, 2001.

MATTOS, Pedro Lincoln C. L. A entrevista não-estruturada como forma de conversação: razões e sugestões para sua análise. Revista de Administração Pública, Rio de Janeiro, v. 4, n. 39, p. 823-847, jul./ago. 2005.

MCKENNA, Christopher D. Agents of adhocracy: management consultants and the reorganization of the executive branch, 1947-1949. Business and Economy History, v. 25, n. 1, p. 101-111, Fall 1996.

PERNAMBUCO (Estado). Secretaria de Fazenda do Estado. Plano estratégico 1999/2002 (versão final). Recife: Sefaz, 1999.

. Comissão Diretora da Reforma do Estado. Plano Diretor da Reforma do Estado. Recife: Cepe, 2000a.

Secretaria de Produção Rural e Reforma Agrária. Análise do relatório de progresso no 2 (R2) do Projeto de Reforma do Estado - Estudo FGV, Ceagepe, Ceasa e Ceagepe Silo Portuário. Recife, 2000b.

Secretaria de Administração e Reforma do Estado. Reestruturação e modernização do aparelho do Estado em Pernambuco: projeto da reforma para o período 2003/2006. Recife: Cepe, 2003.

Secretaria de Administração e Reforma do Estado. Modernização da gestão e reforma institucional do governo de Pernambuco: ações da Secretaria de Administração e Reforma do Estado - Sare. Recife: Cepe, 2005.

Secretaria de Administração e Reforma do Estado. Escola de governo. Disponível em: <www.sare.pe.gov.br>. Acesso em: $10 \mathrm{dez}$. 2005a.

PERNAMBUCO JÁ. Programa de Governo para Mudar Pernambuco: síntese para discussão. Recife, 1998.

PERNAMBUCO (Estado); FUNDAÇÃO GETULIO VARGAS, Escola de Administração de Empresas de São Paulo. Relatório de progresso do Projeto de Reforma do Estado — módulos 1 e 2 - Ceagepe. Recife, 1999a.

$\overline{1 \text { e } 2-}$ Cecon. Recife, $1999 \mathrm{~b}$.

; ___ Relatório de progresso no 2 (R2) do Projeto de Reforma do Estado de Pernambuco - Ceagepe - Ceasa. Recife, 2000a.

; __ Relatório de progresso no 2 (R2) do Projeto de Reforma do Estado de Pernambuco - Cecon. Recife, 2000b. 
; ___ Relatório de progresso no 3 (R3) do Projeto de Reforma do Estado de Pernambuco - Ceagepe - Ceasa. Recife, 2000c. . Relatório de progresso no 3 (R3) do Projeto de Reforma do Estado de Pernambuco - Cecon. Recife, 2000d.

REZENDE, Flávio da Cunha. Por que falham as reformas administrativas? Rio de Janeiro: FGV, 2004.

. Tendências da gestão pública nos países da OCDE. In: LEVY, Evelyn; DRAGO, Pedro Aníbal (Orgs.). Gestão pública no Brasil contemporâneo. São Paulo: Fundap - Casa Civil, 2005.

RIBEIRO, Charles. Desestatização é colocada em xeque. Diário de Pernambuco, Recife, 07 fev. 1999. Política, p. A4.

ROCHA, César. Orçamento revelador. Diário de Pernambuco, Recife, 1 out. 1999. Diário Econômico, p. B2.

ROMÃO. Romão defende reformulações. Diário de Pernambuco, Recife, 7 fev. 1999. Política, p. A4.

SEABRA, Sérgio Nogueira. A nova administração pública e mudanças organizacionais. Revista de Administração Pública, Rio de Janeiro, v. 4, p. 19-43, jul./ago. 2001.

SECRETÁRIOS de Jarbas afirmam que reforma não trará demissões. Diário de Pernambuco, Recife, 31 dez. 1998. Política, p. A2.

SPINK, Peter. Possibilidades técnicas e imperativos políticos em 70 anos de reforma administrativa. In: BRESSER-PEREIRA, Luiz C.; SPINK, Peter (Orgs.). Reforma do Estado e administração pública gerencial. 4. ed. Rio de Janeiro: FGV, 2001.

STAKE, Robert E. Case studies. In: DENZIN, Norman K.; LINCOLN, Ivonna S. (Eds.). Handbook of qualitative research. London: Sage, 1994.

VASCONCELOS, Jarbas. Entrevista: seis meses de governo Jarbas "Eu me preparei para chegar aqui e tenho que vencer a falta de recursos". Diário de Pernambuco, Recife, p. D7, 4 jul. 1999.

. "Vamos sair em breve deste estrangulamento". Jornal do Commercio, Recife, 14 mar. 1999. Política, p. 9. 